\title{
openheart Heart failure in pregnancy: what is the long-term impact of pregnancy on cardiac function? A tertiary care centre experience and systematic review
}

\author{
Anudeep K Dodeja (D) , ${ }^{1,2}$ Francesca Siegel, ${ }^{3}$ Katherine Dodd, ${ }^{2}$ Marwan Ma'ayeh, ${ }^{4}$ \\ Laxmi S Mehta, ${ }^{2}$ Margaret M Fuchs (D) , ${ }^{5}$ Kara M Rood, ${ }^{4}$ May Ling Mah, ${ }^{1}$ \\ Elisa A Bradley (iD ${ }^{2}$
}

\begin{abstract}
- Additional online supplemental material is published online only. To view, please visit the journal online (http://dx.doi.org/10.1136/ openhrt-2021-001587).
\end{abstract}

To cite: Dodeja AK, Siegel F, Dodd $\mathrm{K}$, et al. Heart failure in pregnancy: what is the longterm impact of pregnancy on cardiac function? A tertiary care centre experience and systematic review. Open Heart 2021;8:e001587. doi:10.1136/ openhrt-2021-001587

Received 25 June 2021 Accepted 15 July 2021

Check for updates

(C) Author(s) (or their employer(s)) 2021. Re-use permitted under CC BY-NC. No commercial re-use. See rights and permissions. Published by BMJ.

For numbered affiliations see end of article.

Correspondence to Dr Anudeep K Dodeja; anujassal@gmail.com

\section{ABSTRACT}

Background Women with cardiomyopathy (CM) are often advised against pregnancy due to risk for major adverse cardiovascular events (MACE). However, the impact of CM subtype on maternal MACE is not understood, and so we sought to evaluate the influence of CM phenotype on maternal outcomes, as well as the effect on immediate and late left ventricular function.

Methods We evaluated all pregnant women in our highrisk maternal cardiovascular programme (2009-2019).

Composite maternal MACE included: death, inotrope use, left ventricular assist device, orthotopic heart transplant and/or escalation in transplant listing status, acute decompensated heart failure and sustained ventricular arrhythmia.

Results Among 875 women followed, 32 had CM $(29 \pm 7$ years old, left ventricular ejection fraction (LVEF) $41 \% \pm 12 \%$ ): 3 ischaemic CM (ICM), 10 peripartum CM (PPCM) and 19 non-ICM (NICM). MACE events occurred in 6 (18\%) women (PPCM: 2 (33\%), NICM: 4 (67\%)). There was no difference in LVEF at baseline, however, women with MACE had significantly lower LVEF both early (LVEF: $27 \pm 5 \%$ vs $.41 \pm 2 \%, \mathrm{p}<0.05$ ) and late post partum (LVEF: $28 \pm 5 \%$ vs . $44 \pm 2 \%, p<0.01)$.

Conclusions In this contemporary cohort of women with $\mathrm{CM}$, maternal MACE rates were lower than previously reported, and were less common in PPCM as compared with ICM and NICM. Heart function in women with MACE was negatively impacted immediately after delivery and in late postpartum follow-up, suggesting that pregnancy itself likely has influence on future left ventricular function in women with underlying $\mathrm{CM}$.

\section{INTRODUCTION}

Cardiovascular disease (CVD) is the leading cause of maternal mortality in the USA. ${ }^{1}$ Up to $4 \%$ of pregnant women are affected by CVD, and roughly $15 \%$ is accounted for by cardiomyopathy $(\mathrm{CM}) .{ }^{12} \mathrm{CM}$ affects the heart muscle, and is often categorised by the myopathic phenotype: dilated, restrictive,

\section{Key questions}

What is already known about this subject?

- In prior studies, major adverse cardiac events (MACE) in women with cardiomyopathy (CM) has been reported to be $30 \%$ or higher, forming the basis for the WHO's class IV pregnancy risk category designation. In fact, these women are usually told that pregnancy is high risk and should be avoided. We sought to understand whether the type of underlying CM had any impact on maternal outcomes.

What does this study add?

- In this cohort, we found that MACE occurred in 18\% of patients, significantly lower than what had been reported in the past. However, we also found that women with MACE had worse heart function in the immediate postpartum and at late follow-up, suggesting that pregnancy itself likely has influence on future heart function in women with underlying $\mathrm{CM}$.

How might this impact on clinical practice?

- To our knowledge, no other group has shown that pregnancy impacts late cardiovascular function in women who have CM and MACE events. These data underscore the importance of further research evaluating the late effects of pregnancy on maternal cardiovascular function.

hypertrophic, ischaemic, arrhythmogenic and idiopathic.

Traditionally, women with CM are often advised to avoid pregnancy given the high risk for maternal major adverse cardiovascular events (MACE). ${ }^{3}{ }^{4}$ Nonetheless, with advances in medical care, women with $\mathrm{CM}$ often seek counselling to accurately estimate individual risk in pregnancy. The heterogeneous nature of $\mathrm{CM}$ makes risk stratification challenging. Therefore, we sought to evaluate maternal cardiovascular outcomes in our tertiary care centre's high-risk cardioobstetrics programme, to determine the 
impact of CM phenotype on peripartum and postpregnancy outcomes. Here, we report our findings and qualitatively compare this to systematic literature review from the same time period (2009-2019).

\section{METHODS}

We collected baseline demographic data, type and duration of underlying CM, results from cardiac studies (echocardiogram, cardiac MRI, etc), guideline directed medical therapy (GDMT) use, maternal outcomes, obstetric outcomes and fetal outcomes. To estimate the late effects of pregnancy in women with underlying CM, we also assessed maternal functional class and cardiac function at most recent follow-up, when available. We defined composite maternal MACE (composite MACE) in the setting of pregnancy as any one of the following: maternal death, inotrope use, requirement of left ventricular assist device (LVAD), orthotopic heart transplant (OHT) and/or escalation in OHT listing status, acute decompensated heart failure and sustained ventricular tachycardia (VT) or ventricular fibrillation (VF). All composite MACE events were evaluated up to 1 year after delivery.

Table 1 Demographic data

\begin{tabular}{|c|c|c|c|c|c|}
\hline Variable & $\begin{array}{l}\text { All Patients } \\
(n=32) \\
\text { mean } \pm \text { SEM or } \\
\text { frequency }(\%)\end{array}$ & $\begin{array}{l}\text { Ischaemic } \\
\text { cardiomyopathy } \\
(n=3) \\
\text { mean } \pm \text { SEM or } \\
\text { frequency }(\%)\end{array}$ & $\begin{array}{l}\text { Peripartum } \\
\text { cardiomyopathy } \\
(n=10) \\
\text { mean } \pm \text { SEM or } \\
\text { frequency }(\%)\end{array}$ & $\begin{array}{l}\text { Other }(n=19) \\
\text { mean } \pm \text { SEM or } \\
\text { frequency }(\%)\end{array}$ & $P$ value \\
\hline \multicolumn{6}{|l|}{ Demographics } \\
\hline Age (years) & $29 \pm 7$ & $31 \pm 4$ & $30 \pm 2$ & $29 \pm 2$ & 0.82 \\
\hline Gravida & $3 \pm 3$ & $8 \pm 2$ & $2 \pm 1$ & $3 \pm 1$ & $<0.01$ \\
\hline Para & $1 \pm 1$ & $1 \pm 1$ & $2 \pm 1$ & $1 \pm 1$ & 0.19 \\
\hline $\mathrm{BMI}\left(\mathrm{kg} / \mathrm{m}^{2}\right)$ & $33 \pm 9$ & $42 \pm 5$ & $32 \pm 3$ & $32 \pm 2$ & 0.20 \\
\hline \multicolumn{6}{|l|}{ Comorbid illness } \\
\hline Hypertension & $18(31)$ & $2(66)$ & $4(40)$ & $12(63)$ & 0.46 \\
\hline Diabetes & $9(28)$ & $1(33)$ & $4(40)$ & $4(21)$ & 0.19 \\
\hline CKD & $1(3)$ & $0(0)$ & $0(0)$ & $1(3)$ & 0.59 \\
\hline Obesity & $20(63)$ & $3(100)$ & $6(60)$ & $12(63)$ & 0.97 \\
\hline \multicolumn{6}{|l|}{ Heart function } \\
\hline NYHA FC>2 & $13(45)$ & $0(0)$ & $3(30)$ & $10(53)$ & 0.33 \\
\hline Ejection fraction (\%) & $41 \pm 12$ & $35 \pm 12$ & $50 \pm 5$ & $39 \pm 3$ & 0.24 \\
\hline Beta-blocker & $26(81)$ & $2(66)$ & $4(40)$ & $16(84)$ & 0.05 \\
\hline Angiotensin inhibitor & $17(53)$ & $1(33)$ & $4(40)$ & $12(63)$ & 0.38 \\
\hline Aldosterone antagonist & $5(16)$ & $1(33)$ & $0(0)$ & $4(21)$ & 0.11 \\
\hline Sacubitril/valsartan & 2 (6) & $0(0)$ & $0(0)$ & $2(11)$ & 0.34 \\
\hline \multicolumn{6}{|l|}{ Obstetric } \\
\hline Gestational diabetes & $6(19)$ & $1(33)$ & $4(40)$ & $1(5)$ & 0.06 \\
\hline HDP & $12(38)$ & $1(33)$ & $5(50)$ & $6(32)$ & 0.53 \\
\hline Estimated blood loss (mL) & $590 \pm 602$ & $367 \pm 349$ & $794 \pm 191$ & $518 \pm 138$ & 0.41 \\
\hline Spontaneous vaginal & $11(34)$ & $1(33)$ & $5(10)$ & $5(26)$ & 0.22 \\
\hline Operative vaginal & $9(28)$ & $1(33)$ & $4(40)$ & $4(21)$ & 0.22 \\
\hline Caesarean & $12(38)$ & $1(33)$ & $1(10)$ & $10(53)$ & 0.22 \\
\hline Maternal VTE & $1(3)$ & $0(0)$ & $0(0)$ & $1(5)$ & 0.59 \\
\hline \multicolumn{6}{|l|}{ Fetal } \\
\hline Birth weight (g) & $2810 \pm 664$ & $2941 \pm 398$ & $2015 \pm 218$ & $2696 \pm 158$ & 0.48 \\
\hline APGAR $1 \mathrm{~min}$ & $7.3 \pm 2.1$ & $8.3 \pm 1.2$ & $7.1 \pm 1.0$ & $7.3 \pm 1.0$ & 0.66 \\
\hline APGAR 5 min & $8.6 \pm 1$ & $9.0 \pm 0.4$ & $8.8 \pm 0.2$ & $8.4 \pm 0.2$ & 0.28 \\
\hline
\end{tabular}

APGAR Score, Appearance, Pulse, Grimace, Activity, Respiration; BMI, body mass index; CAD, coronary artery disease; CKD, chronic kidney disease; HDP, hypertensive disorders of pregnancy; NYHA FC, New York Heart Association Functional Class; SEM, SE of the mean; VTE, venous thromboembolic events. 


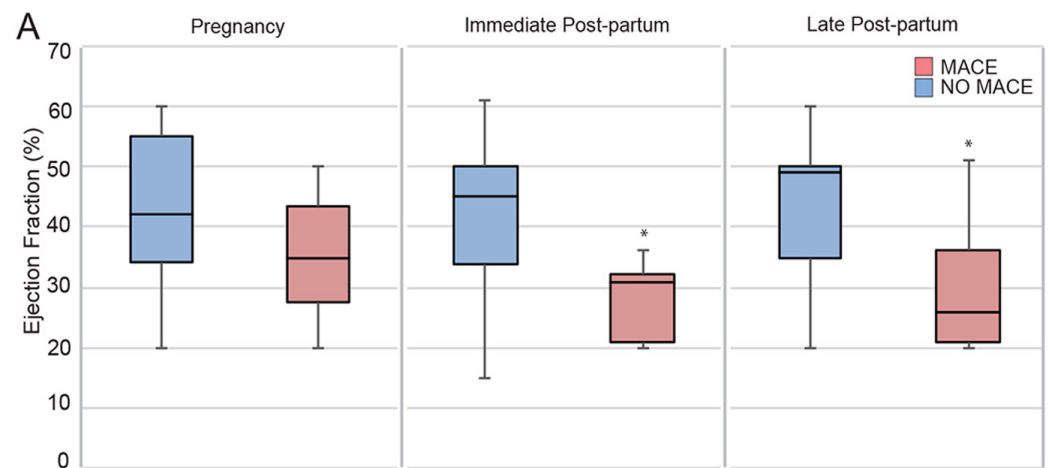

B
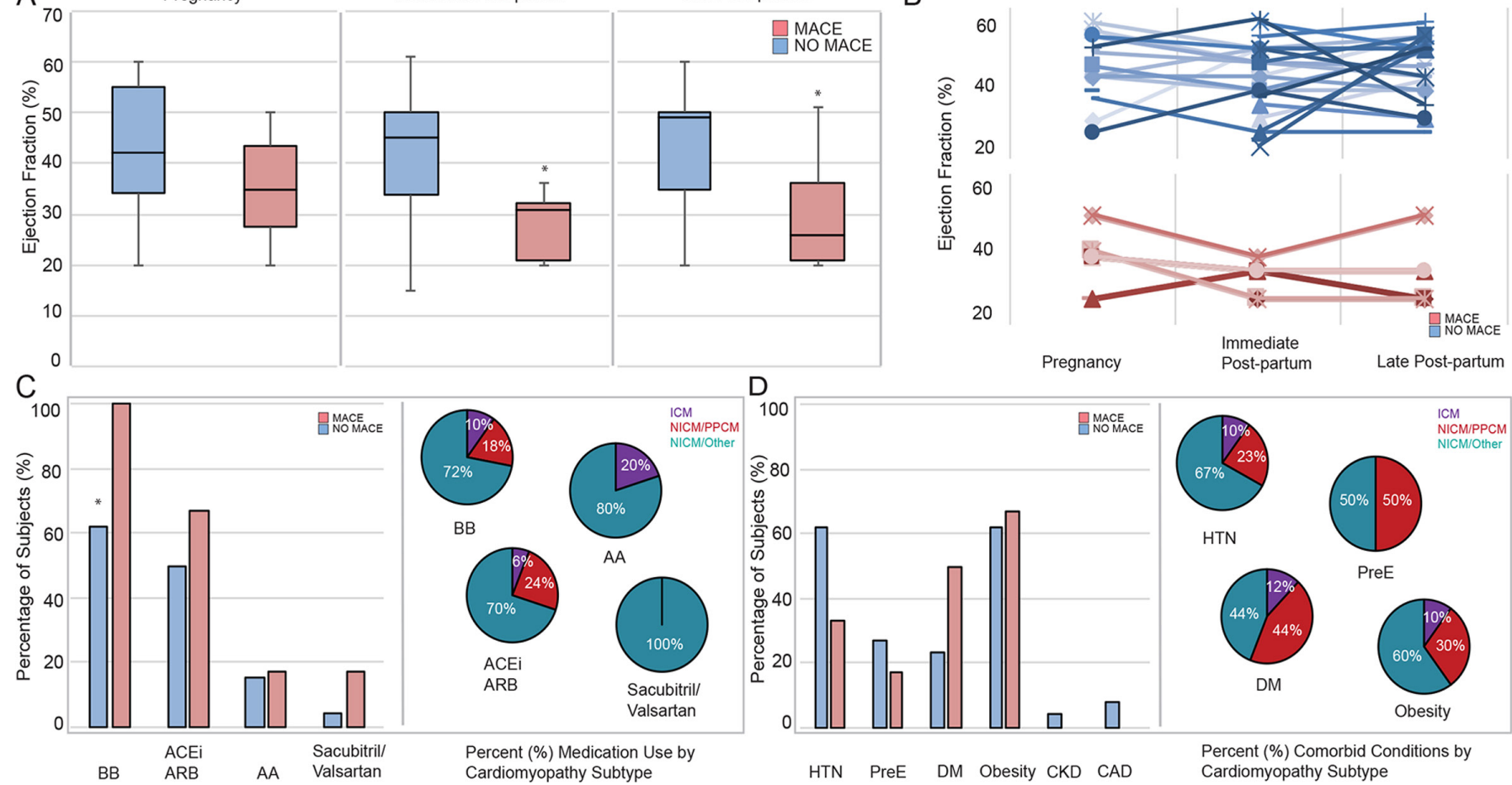

Figure 1 Maternal cardiovascular outcomes. In 32 women with underlying cardiomyopathy (CM) and pregnancy, six women had a major adverse cardiovascular event (MACE). Left ventricular ejection fraction (LVEF) at baseline was similar in the mace and no mace groups, however, women with mace had lower LVEF in the immediate post partum $(27 \% \pm 5 \%$ vs $41 \pm 2 \%, p<0.05)$ and at late follow-up $(28 \% \pm 5 \%$ vs $44 \pm 2 \%, p<0.01)$. (A) Subject-level data indicating EF in pregnancy, immediately post partum and late post partum in those with and without mace are shown (B) women with mace events were more likely to be taking a beta blocker, however, there was no difference in other cardiovascular medication $(C)$ or underlying comorbid medical illness (D) based on subtype of CM. The pie charts demonstrate the proportion of women with medication prescription or comorbid disease prior to pregnancy, relative to the subtype of $\mathrm{CM}(\mathrm{C}, \mathrm{D})$. CAD, coronary artery disease; CM, cardiomyopathy; CKD, chronic kidney disease; NICM, non-ischaemic CM; PPCM, peripartum CM.

In this study, we sought to identify women with (acute or chronic) CM who underwent pregnancy. Women were included in the study cohort if they had a diagnosis of cardiomyopathy prior to pregnancy. Women with a prior history of cardiomyopathy with recovered ventricular function were also included in this cohort. We stratified the subtype of $\mathrm{CM}$ by underlying aetiology into three groups: (1) peripartum CM (PPCM), ischaemic CM (ICM) and non-ICM (NICM). PPCM was defined as left ventricular ejection fraction (LVEF) $<45 \%$ in the last month of pregnancy or within 5 months following delivery, and where no other cause of heart failure (HF) was found. ICM was defined in women with a prior myocardial infarction as the source of systolic dysfunction. The aetiology for NICM included: dilated CM of unknown cause, hypertrophic CM, drug induced, infiltrative diseases, rheumatic conditions, restrictive or familial/genetic CM.

Maternal comorbid medical illness was assessed in the cohort and is outlined in table 1. Gestational hypertension was and subdivided based on the aetiology of gestational hypertension (pre-eclampsia without severe features, pre-eclampsia with severe features, pre-eclampsia superimposed on chronic hypertension). We also evaluated diabetic status and classified diabetes as: type 1 diabetes mellitus, type 2 diabetes mellitus and gestational diabetes.
Obstetric outcomes collected included the location of maternal labour and delivery. Delivery site was coded as (1) general (labour/delivery) obstetric floor (noncritical care bed), (2) obstetric operating room or (3) heart hospital. The route of delivery was defined as: (1) vaginal, (2) operative vaginal (indicating forceps or vacuum delivery) or (3) caesarean section. When the patient delivered by caesarean section, the reason was indicated (dystocia, non-reassuring fetal status, abnormal presentation, elective or prior caesarean section). We also assessed peripartum analgesia (none, epidural, patient controlled analgesia pump, spinal or general sedation) and whether or not any advanced monitoring was used (central venous catheter or arterial line). In women who underwent induction, the indications for induction included: intrauterine growth restriction, hypertension/pre-eclampsia or other maternal medical problem.

Fetal outcomes evaluated were the birth status of the fetus (live birth, stillbirth, miscarriage, abortion) as well as the highest level of resuscitation required (well-baby, transition care nursery or neonatal intensive care unit). Finally, we evaluated any major congenital anomalies, represented in this cohort as: renal anomalies, hypospadias and ventricular septal defect. 


\begin{tabular}{|c|c|c|c|}
\hline Variable & $\begin{array}{l}\text { Composite } \\
\text { MACE event } \\
(n=6) \\
\text { Mean } \pm \text { SEM or } \\
\text { frequency }(\%)\end{array}$ & $\begin{array}{l}\text { No composite } \\
\text { MACE event } \\
(n=26) \\
\text { Mean } \pm \text { SEM or } \\
\text { frequency }(\%)\end{array}$ & $P$ value \\
\hline \multicolumn{4}{|l|}{ Demographics } \\
\hline BMI & $30 \pm 5$ & $34 \pm 9$ & 0.10 \\
\hline Age & $29 \pm 9$ & $29 \pm 6$ & 0.90 \\
\hline ICM & $0(0)$ & $3(12)$ & 0.28 \\
\hline PPCM & $2(33)$ & $8(31)$ & 0.28 \\
\hline NICM & $4(67)$ & $15(57)$ & 0.28 \\
\hline \multicolumn{4}{|l|}{ Comorbid illness } \\
\hline Hypertension & $2(33)$ & $16(62)$ & 0.21 \\
\hline Diabetes & $3(50)$ & $6(23)$ & 0.21 \\
\hline $\mathrm{CAD}$ & $0(0)$ & $2(8)$ & 0.35 \\
\hline CKD & $0(0)$ & $1(4)$ & 0.52 \\
\hline Obesity & $4(67)$ & $16(62)$ & 0.81 \\
\hline \multicolumn{4}{|l|}{ Heart function } \\
\hline NYHA FC>2 & $4(67)$ & $8(33)$ & 0.30 \\
\hline LVEF (\%) & $35 \pm 11$ & $43 \pm 12$ & 0.22 \\
\hline \multicolumn{4}{|c|}{ Cardiac medications (pre-pregnancy) } \\
\hline Beta-blocker & $6(100)$ & $16(62)$ & $<0.05$ \\
\hline Angiotensin inhibitor & $4(67)$ & $13(50)$ & 0.46 \\
\hline $\begin{array}{l}\text { Aldosterone } \\
\text { antagonist }\end{array}$ & $1(17)$ & $4(67)$ & 0.94 \\
\hline Sacubitril/valsartan & $1(17)$ & $1(4)$ & 0.30 \\
\hline \multicolumn{4}{|l|}{ Obstetric } \\
\hline Gestational diabetes & $2(33)$ & $4(15)$ & 0.34 \\
\hline HDP & $1(17)$ & $11(42)$ & 0.45 \\
\hline $\begin{array}{l}\text { Estimated blood loss } \\
(\mathrm{mL})\end{array}$ & $1058 \pm 231$ & $482 \pm 111$ & 0.03 \\
\hline Spontaneous vaginal & $2(33)$ & $9(35)$ & 0.08 \\
\hline Operative vaginal & $0(0)$ & $9(35)$ & 0.08 \\
\hline Caesarean & $4(67)$ & $8(30)$ & 0.08 \\
\hline \multicolumn{4}{|l|}{ Fetal } \\
\hline Birth weight (g) & $2813 \pm 283$ & $2820 \pm 136$ & 0.98 \\
\hline APGAR 1 min & $8.2 \pm 0.9$ & $7.1 \pm 0.4$ & 0.26 \\
\hline APGAR 5 min & $8.5 \pm 0.3$ & $8.6 \pm 0.2$ & 0.74 \\
\hline
\end{tabular}

APGAR Score, Appearance, Pulse, Grimace, Activity and Respiration; $\mathrm{BMI}$, body mass index; CAD, coronary artery disease; CKD, chronic kidney disease; HDP, hypertensive disorders of pregnancy; ICM, ischaemic cardiomyopathy; LVEF, left ventricular ejection fraction; MACE, major adverse cardiovascular events; NICM, non-ICM; NYHA FC, New York Heart Association Functional Class; PPCM, peripartum $\mathrm{CM}$; SEM, SE of the mean; VTE, venous thromboembolic events.

Descriptive statistics were generated on demographic variables and reported as mean \pm SEM and frequency (\%) where appropriate on all patients. We analysed and reported the same findings on women with each subtype of CM in the cohort (ICM, PPCM, NICM). Maternal, obstetric and fetal outcomes in the entire population and within the three subtypes of CM were also analysed. We evaluated and compared demographic and clinical variables in women with versus without composite MACE events. All definitions of variables collected are available in the online supplemental methods. Where appropriate, we used one-way analysis of variance to evaluate any differences in continuous variables and $\chi^{2}$ to evaluate for any potential differences in categorical variables. An $\alpha<0.05$ was defined as the cut-off for reducing the probability of a type 1 error. JMP Pro, V.12.2.0. SAS Institute 1989-2019 was used to perform all statistical analyses.

Full methods for the systematic review are available in online supplemental data file. It was not appropriate or possible to involve patients or the public in the design, or conduct, or reporting, or dissemination plans of our research.

\section{RESULTS \\ Tertiary care centre}

We followed 875 women (979 pregnancies) of which 32 had CM $(29 \pm 7$ years old, gravida $3 \pm 3$, para $1 \pm 1$, LVEF $41 \% \pm 12 \%)$. CM phenotypes included: three ICM, 10 PPCM, and 19 NICM. At baseline, women with underlying ICM had a higher number of prior gestations $(8 \pm 2 \mathrm{vs}$. $2 \pm 1$ PPCM and vs $1 \pm 1$ NICM, $\mathrm{p}<0.01)$. Prior to pregnancy, 22 women were prescribed beta-blockers, 17 angiotensin enzyme converting inhibitors, 5 aldosterone antagonists and 2 sacubitril/valsartan. Women with the NICM phenotype were most likely to have used beta-blocker therapy (16 (84\%) vs $4(40 \%)$ PPCM \& vs $2(66 \%)$ ICM, p=0.05) (table 1, figure 1).

Composite MACE events occurred in 6 (18\%) women (2 (33\%) PPCM, 4 (67\%) NICM), who were more likely to be have received beta blocker therapy $(6(100 \%)$ vs 16 $(62 \%), \mathrm{p}<0.05)$. These women were otherwise similar to women without MACE in terms of baseline characteristics (table 2). Specific details regarding the type of maternal composite MACE event and intrapartum management are available in table 3. Although there was no difference in LVEF at baseline (MACE vs No MACE: $35 \pm 11 \%$ vs . $43 \pm 12 \%, \mathrm{p}=0.22$ ), women with MACE had a significant reduction in LVEF post partum $(27 \% \pm 5 \%$ vs $41 \pm 2 \%$, $\mathrm{p}<0.05)$ at $32 \pm 13$ days. The same women continued to have persistently depressed LVEF $(28 \% \pm 5 \%$ vs $44 \pm 2 \%$, $\mathrm{p}<0.01)$ at late a follow-up of $1.4 \pm 0.3$ years postdelivery (figure 1).

Of the 32 women included in this cohort, 2 (6\%) carried a twin gestation, resulting in 34 live born neonates. The average maternal length of stay was $7 \pm 6$ days. Complications of pregnancy included: hypertensive disorders in 12 $(38 \%)$, gestational diabetes in $6(19 \%)$, fetal intrauterine growth restriction in $2(6 \%)$, and preterm labour in 2 $(6 \%)$. Mode of delivery was caesarean section (operative) in $17(54 \%)$, spontaneous vaginal in $11(34 \%)$ and operative vaginal in $4(12 \%)$. The mean gestational age at delivery was $36.5 \pm 2.8$ weeks, and 8 of the women delivered preterm ( $<37$ weeks gestation). In women with $\mathrm{CM}$, the average blood loss associated with delivery was $590 \pm 602$ $\mathrm{mL}$, and three received blood transfusion (figure 2). 


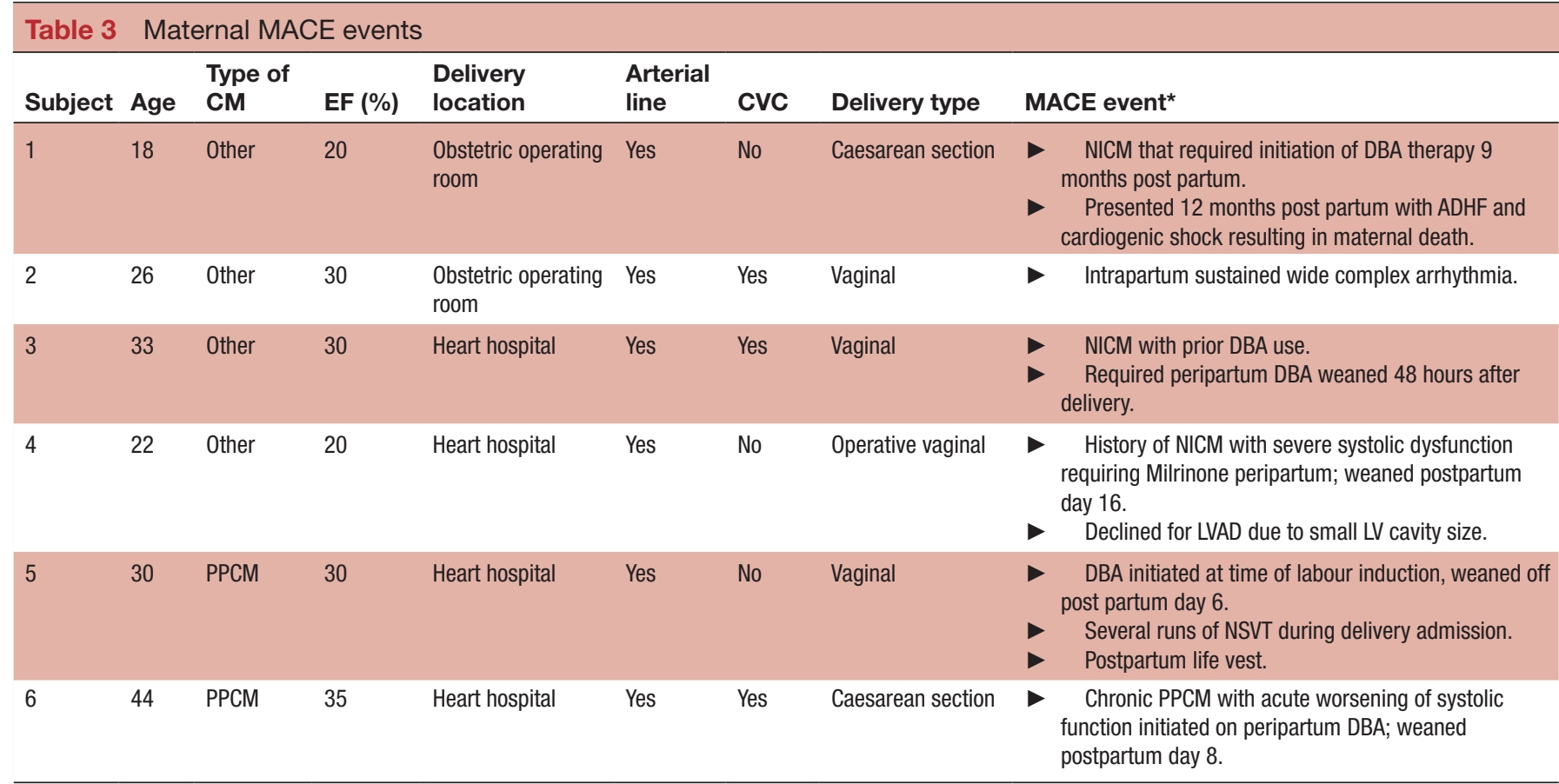

${ }^{*}$ Referring to composite MACE events include: maternal death, inotrope use, LVAD, OHT or listingstatus change, acute decompensated heart failure or sustained ventricular arrhythmia up to 1-year post partum.

ADHF, acute decompensated heart failure; CM, cardiomyopathy; CVC, central venous catheter; DBA, dobutamine; EF, ejection fraction; LV, left ventricle; LVAD, left ventricular assist device; MACE, major adverse cardiovascular event; NICM, non-ischaemic cardiomyopathy; NSVT, nonsustained ventricular tachycardia; OHT, orthotopic heart transplant; PPCM, peripartum cardiomyopathy.

There were no fetal or neonatal deaths in this cohort. The majority of infants $(22(65 \%))$ recovered in the wellbaby unit (length of stay $9 \pm 23$ days). The average birth weight was 2,810 6664 grams, and $3(9 \%)$ infants met small for gestational age criteria. Neonatal intensive care unit admission was required in 7 (21\%), although only 1 (3\%) had an Appearance, Pulse, Grimace, Activity and Respiration score $<7$ at 5 min of life. We assessed obstetric and fetal outcomes in women with MACE and found that women with MACE were likely to have increased blood loss at delivery $(1058 \pm 231 \mathrm{~mL}$ vs $483 \pm 111 \mathrm{~mL}, \mathrm{p}<0.05)$ (table 2, figure 2).

\section{Obstetric}

Labour induction was attempted in 13 (41\%) women due to: intrauterine growth restriction in $1(8 \%)$, hypertension/pre-eclampsia in $4(31 \%)$ or for other medical problems in $8(62 \%)$. The most common delivery route was caesarean section $(17(54 \%)$ vs spontaneous vaginal 11 $(34 \%)$ and operative vaginal $(4(12 \%))$. Indications for caesarean section included: shoulder dystocia in $2(12 \%)$, non-reassuring fetal status in $5(29 \%)$, abnormal presentation in $2(12 \%)$ and elective/prior caesarean section in $8(47 \%)$. There were very few maternal obstetric events, and they included: clinical chorioamnionitis in $1(3 \%)$, postpartum haemorrhage in $3(9 \%)$, venothromboembolic event in $1(3 \%)$ and acute kidney injury in $2(6 \%)$. There were no strokes, respiratory distress, disseminated intravascular coagulopathy, ruptured liver or retained products of conception.

\section{Fetal}

Respiratory complications (respiratory distress syndrome, transient tachypnoea of the newborn, need for continuous positive airway pressure and/or intubation) occurred in $10(29 \%)$ of neonates, sepsis in $1(3 \%)$, hypoglycaemic requiring intravenous glucose in $5(15 \%)$ and hyperbilirubinaemia requiring phototherapy in $4(12 \%)$. There was no relationship between maternal beta-blocker use and fetal hypoglycaemic. There were four congenital anomalies which included: ventricular septal defect in two $(6 \%)$, hypospadias in one $(3 \%)$, and renal anomaly in one $(3 \%)$. There was no meconium aspiration syndrome, respiratory distress syndrome, seizure, neonatal aspiration syndrome or necrotising enterocolitis.

\section{Systematic review}

After the initial search (online supplemental data file) we reviewed 50 studies in depth (26 cohort; 24 case-series) figure 3 , and summarised results according to type of CM (2 (4\%) ICM, 14 (28\%) PPCM, 33 (68\%) NICM) (table 3 ). We found no difference in MACE or maternal death between the tertiary care centre and systematic review data, or in maternal death in any of the $\mathrm{CM}$ subtypes (table 4 ).

\section{Ischaemic CM}

Data on ICM during pregnancy is scarce, and out of the nine ICM studies reviewed, only two met inclusion criteria. ${ }^{56}$ In these studies, there were 193 women (200 pregnancies), and although LVEF was not reported in 

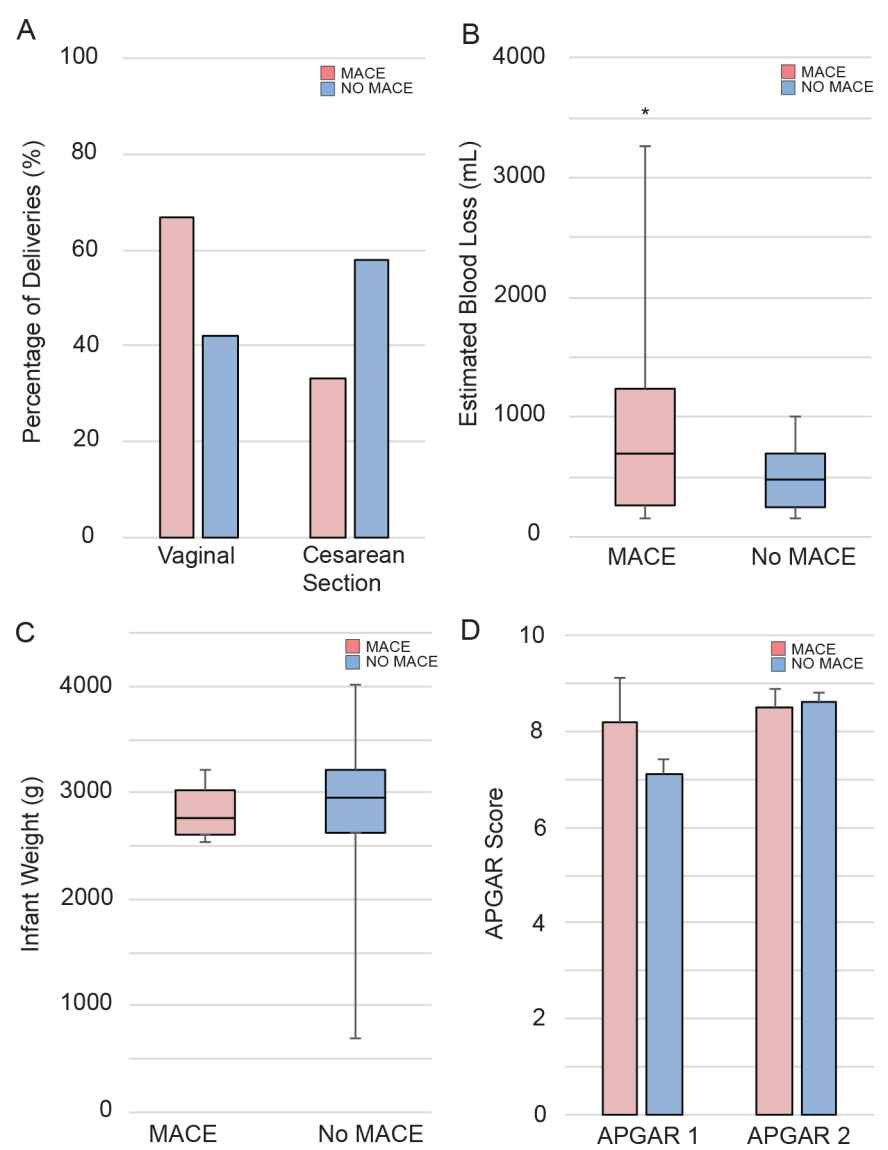

Figure 2 Obstetric and fetal outcomes. There was no difference in the mode of delivery when women with MACE and no MACE were examined (MACE vaginal $4(67 \%)$ vs caesarean $2(33 \%)$ and no mace vaginal $11(42 \%)$ vs 15 $(58 \%), p=0.28)(A)$. However, women with mace were more likely to have higher estimated blood loss with delivery $(1058 \pm 231 \mathrm{~mL}$ vs $483 \pm 111 \mathrm{~mL}, \mathrm{p}<0.05)(B)$. Infant weight was insignificantly different in women with MACE $(2813 \pm 283$ $\mathrm{g}$ vs $2820 \pm 136 \mathrm{~g}, \mathrm{p}=0.99$ ), as was 1 and $5 \mathrm{~min}$ APGAR score (C, D). APGAR, Appearance, Pulse, Grimace, Activity and Respiration; MACE, major adverse cardiovascular events.

$58(29 \%)$, LVEF was normal in $27(19 \%)$ of women. ${ }^{56}$ In total, outcomes reported in both studies included: 19 (10\%) VT/VF episodes and $11(6 \%)$ maternal deaths. In the first case series, MACE identified included: 56 $(37 \%)$ with heart failure/cardiogenic shock, 18 (12\%) with ventricular arrhythmias, $29(19 \%)$ with recurrent angina/MI and 10 (7\%) with maternal mortality. ${ }^{6}$ In the second study, composite MACE occurred in $5(10 \%)$ of the 50 pregnancies, however, it increased to $17(34 \%)$ if angina, stroke, pulmonary emboli and atrial arrhythmias were included (online supplemental table 2).

\section{Peripartum CM}

We reviewed 59 studies in depth that evaluated PPCM, and 34 met final inclusion representing 41069 women. $^{7-40}$ Postpartum follow-up time ranged from 0 to 14 years, and death, LVAD requirement, and OHT were the most commonly reported MACE. Maternal mortality data was available in $40780(99 \%)$ and MACE in 40826 (99\%),

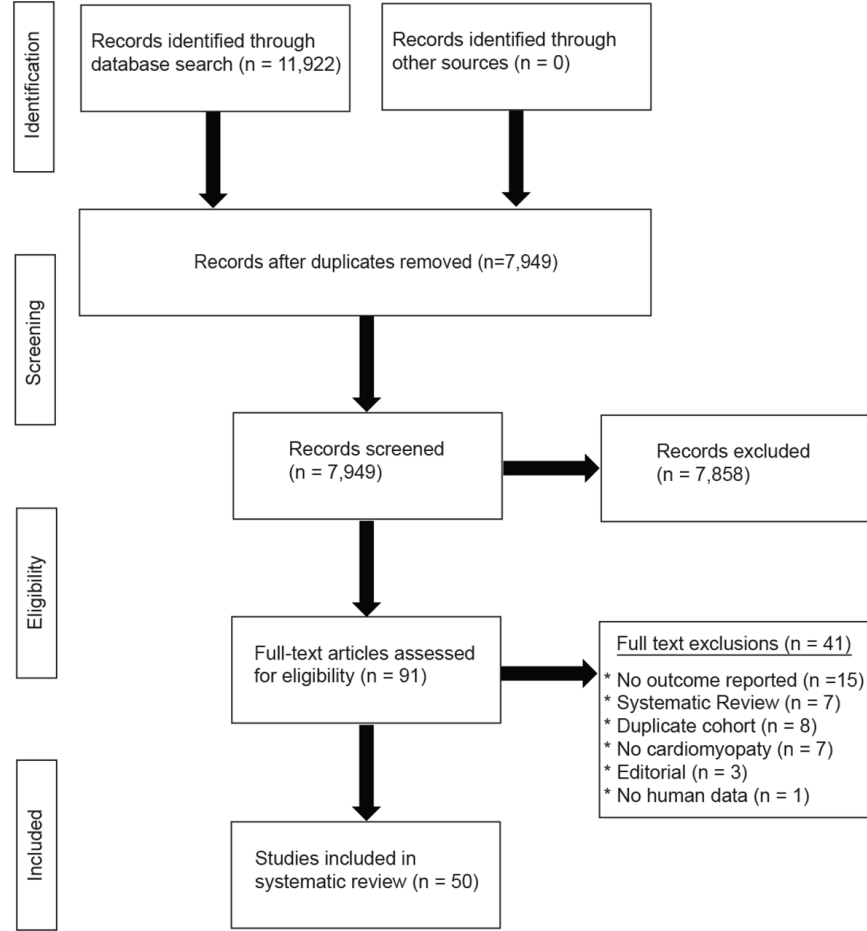

Figure 3 Flowsheet of systematic review data search. Flowsheet of studies identified, screened and reviewed for inclusion in the systematic review.

and occurred in $612(1.5 \%)$ and $4972(12 \%)$, respectively. Composite MACE events are outlined in online supplemental table 3 .

\section{Other CM}

Among the 23 non-ICM/non-PPCM studies reviewed, there were 14 that met the inclusion criteria (353 women; (LVEF reported in $155(44 \%))^{41-50}$ (online supplemental S51-54). LVEF was $<50 \%$ in $43(28 \%)$ women and there were $222(63 \%)$ patients assessed for VT/VF and 304 (86\%) for maternal death, with VT/VF occurring in 34 $(15 \%)$ and maternal death in $7(2 \%)$. Composite MACE was assessed in a minority of studies and was not readily amalgamated due to the heterogeneous format of the data. Specific composite MACE data are reported in online supplemental table 4 .

\section{DISCUSSION}

Although absolute maternal mortality is declining in the general obstetric population, CVD-mediated maternal mortality is increasing. Perhaps this reflects overall improved morbidity and mortality in CVD, including women of childbearing age, who are interested in pregnancy. Women with CM and reduced LVEF are often quoted a $30 \%$ or higher rate of sustaining MACE during pregnancy. ${ }^{2}$ Over the last decade, in our tertiary care centre, we followed 32 women (3\% total programme volume) with CM. In this study MACE was broadly defined, in order to capture all probable maternal MACE, yet the rate was only $18 \%$, and the majority of women were prescribed GDMT prior to pregnancy. It 
Table 4 Cardiomyopathy subtype and MACE rates

\begin{tabular}{|c|c|c|c|c|}
\hline \multirow[b]{2}{*}{$\begin{array}{l}\text { Cardiomyopathy } \\
\text { Subtype }\end{array}$} & \multicolumn{2}{|c|}{ Tertiary care centre } & \multicolumn{2}{|c|}{ Systematic review } \\
\hline & $\begin{array}{l}\text { Assessed, } \\
\text { n (\%) }\end{array}$ & $\begin{array}{l}\text { Affected, } \\
\text { n (\%) }\end{array}$ & $\begin{array}{l}\text { Assessed, } \\
\text { n (\%) }\end{array}$ & $\begin{array}{l}\text { Affected, } \\
\text { n (\%) }\end{array}$ \\
\hline ICM & 3 & & 193 & \\
\hline Inotrope & $3(100)$ & 0 & 0 & NR \\
\hline LVAD & & 0 & 0 & NR \\
\hline OHT listing & & 0 & 0 & NR \\
\hline VT/VF & & 0 & $193(100)$ & $19(10)$ \\
\hline Maternal death & & 0 & $193(100)$ & $11(6)$ \\
\hline Composite MACE & & 0 & $193(100)$ & $108(56)$ \\
\hline PPCM & 10 & & 41069 & \\
\hline Inotrope & $10(100)$ & $2(20)$ & $240(0.6)$ & $2(0.8)$ \\
\hline LVAD & & 0 & 35237 (86) & $541(1.5)$ \\
\hline OHT listing & & 0 & $661(1.6)$ & $29(4.4)$ \\
\hline VT/NF & & $1(10)$ & $1132(2.8)$ & 217 (19) \\
\hline Maternal death & & $1(10)$ & 40780 (99) & $612(1.5)$ \\
\hline Composite MACE & & $4(40)$ & 40826 (99) & $4972(12)$ \\
\hline NICM & 19 & & 353 & \\
\hline Inotrope & $19(100)$ & $2(11)$ & 0 & NR \\
\hline LVAD & & 0 & 0 & NR \\
\hline OHT listing & & 0 & 0 & NR \\
\hline VT/NF & & 0 & $222(63)$ & $34(15)$ \\
\hline Maternal death & & 0 & $304(86)$ & $7(2)$ \\
\hline Composite MACE & & $2(11)$ & 0 & $\mathrm{NR}$ \\
\hline
\end{tabular}

ICM, ischaemic cardiomyopathy; LVAD, left ventricular assist device; MACE, major adverse cardiovascular event; NICM, non-ischaemic cardiomyopathy; NR, not reported; OHT, orthotopic heart transplant; PPCM, peripartum cardiomyopathy; VT/VF, ventricular tachycardia/ ventricular fibrillation.

is unclear whether or not GDMT for heart failure itself had an impact on the maternal MACE rate in such women. However, our data would at minimum imply that outcomes may be better than previously reported. Despite this, it is important to highlight that although LVEF prior to pregnancy was not different in the MACE and non-MACE cohorts, women with MACE in pregnancy demonstrated overall worse heart function immediately postpartum and at late follow-up, implying that the negative impact of pregnancy on heart function may be sustained in women with underlying CM.

From the comprehensive systematic review of published MACE events in women with diverse categories of CM, we found that ventricular arrhythmia and death were the only two MACE events reported consistently (VT/VF $15 \%-19 \%$, maternal death 2\%-6\%) and were not dissimilar between CM subtypes, similar to the tertiary care centre dataset. However, we acknowledge that the systematic review data is likely skewed due to disproportionate representation of PPCM.

From an obstetric standpoint, the operative delivery rate for our cohort was 54\%, significantly higher than the national average of $32 \%$ (online supplemental S55).
Hypertensive disorders of pregnancy (HDP) were found in $28 \%$ of this $\mathrm{CM}$ cohort, which is also higher than expected (8\%) (online supplemental S5 and S6) and likely due to the higher proportion of PPCM, and the relationship between HDP and PPCM (online supplemental S5 and S7). Bleeding events were more significant in women with MACE, however, this may be explained by differences in operative delivery rates in women with MACE versus those without (67\% vs $30 \%$ ), although not statistically significant $(\mathrm{p}=0.08)$. MACE was not impacted by mode or location of delivery, and offspring from women with $\mathrm{CM}$ did not have any significant adverse neonatal outcomes, providing some reassurance that maternal risk does not necessarily increase neonatal risk.

\section{Limitations}

There are several limitations to this study. First, the overall number of women from the single centre cardioobstetrics programme, although large for one site, is relatively small. Second, data is gathered retrospectively and so it is unclear whether or not the associations demonstrated are applicable to prospective cohorts. Third, there were disproportionate numbers of women with each 
subtype of CM. More specifically, in both the single-centre and systematic review data, the ICM cohort was small. In addition, there was a disproportionate representation of PPCM in the systematic review cohort. Each of these may have skewed the findings relative to the specific type of underlying CM. Fourth, we recognise the decision about inotrope prescription relies on clinical approach and may be, in part, subjective based on the clinical scenario and assessment by the treatment team at the time of presentation. Additionally, although qualitative analysis was performed, heterogeneity in reported MACE events and the assessment of left ventricular dysfunction prohibited any meaningful analysis between the single-centre group and systematic review generated data. Finally, we conducted a through systematic review, however inclusion of case series and with $<10$ subjects can pose a risk for publication bias of unusual or difficult cases.

\section{CONCLUSION}

In this contemporary cohort of women with CM, the composite maternal MACE rate was lower than previously reported. However, LVEF in women with MACE was negatively impacted immediately after delivery and in late postpartum follow-up, suggesting that pregnancy itself likely has influence on future heart function in women with CM. Women with CM who had maternal MACE also demonstrated higher peripartum bleeding risk, yet other obstetric and fetal outcomes were reassuring.

The findings of this study are important to convey to women with $\mathrm{CM}$ who are contemplating pregnancy. It is reassuring that the MACE rate is likely lower than what has previously been reported. However, the longterm impact of pregnancy on heart function is a serious consequence and cannot be understated. In our tertiary care centre cohort, PPCM and NICM loosely appear to hold higher risk for MACE. However, numbers are small and this area request further broad investigation. Future studies collecting data on women with diverse CM phenotypes will be required to determine exactly which women are of higher risk during the incident pregnancy and in subsequent pregnancies.

\section{Author affiliations \\ ${ }^{1}$ Division of Cardiology, Nationwide Children's Hospital, Columbus, Ohio, USA ${ }^{2}$ Department of Internal Medicine, Division of Cardiovascular Medicine, The Ohio State University, Columbus, Ohio, USA \\ ${ }^{3}$ The Ohio State University College of Medicine, Columbus, Ohio, USA \\ ${ }^{4}$ Department of Obstetrics \& Gynecology, Division of Maternal Fetal Medicine, The Ohio State University, Columbus, $\mathrm{OH}$, USA \\ ${ }^{5}$ Mayo Clinic Division of Cardiovascular Diseases, Rochester, Minnesota, USA}

Contributors AKD: Project design, data collection, analysis, creation of tables and figures, systematic review of non-ischaemic cardiomyopathy, manuscript draft, final edits. FS: Data collection, analysis, manuscript draft and final edits. KD: Project conception, project design, data collection, analysis, manuscript draft and final edits. MM: Data collection, analysis of obstetric and fetal outcomes, manuscript draft and final edits. LSM: Systematic review of ischaemic cardiomyopathy, manuscript draft and final edits. MMF: Systematic review of peripartum cardiomyopathy, manuscript draft and final edits. KMR: Data collection, analysis of obstetric and fetal outcomes, manuscript draft and final edits. MLM: Systematic review of peripartum cardiomyopathy, manuscript draft and final edits. EAB: Project conception, design, data analysis, creation of tables and figures, manuscript draft and final edits.

Funding This work was supported by Elisa Bradley's, grant number NIH K08HL148701.

Competing interests None declared.

Patient consent for publication Not required.

Ethics approval For tertiary care centre derived data, we received approval from the local Institutional Review Board, and evaluated pregnancies in all women, followed by the high-risk cardio-obstetrics team (1 January 2009-1 August 2019).

Provenance and peer review Not commissioned; internally peer reviewed.

Data availability statement All data relevant to the study are included in the article or uploaded as online supplemental information.

Open access This is an open access article distributed in accordance with the Creative Commons Attribution Non Commercial (CC BY-NC 4.0) license, which permits others to distribute, remix, adapt, build upon this work non-commercially, and license their derivative works on different terms, provided the original work is properly cited, appropriate credit is given, any changes made indicated, and the use is non-commercial. See: http://creativecommons.org/licenses/by-nc/4.0/.

ORCID iDs

Anudeep K Dodeja http://orcid.org/0000-0003-4462-3114

Margaret M Fuchs http://orcid.org/0000-0002-6820-5681

Elisa A Bradley http://orcid.org/0000-0003-1479-2988

\section{REFERENCES}

1 Petersen EE, Davis NL, Goodman D, et al. Vital Signs: PregnancyRelated Deaths, United States, 2011-2015, and Strategies for Prevention, 13 States, 2013-2017. MMWR Morb Mortal Wkly Rep 2019;68:423-9.

2 Regitz-Zagrosek V, Roos-Hesselink JW, Bauersachs J, et al. 2018 ESC guidelines for the management of cardiovascular diseases during pregnancy. Eur Heart J 2018;39:3165-241.

3 American College of Obstetricians and Gynecologists' Presidential Task Force on Pregnancy and Heart Disease and Committee on Practice Bulletins-Obstetrics. ACOG practice Bulletin No. 212: pregnancy and heart disease. Obstet Gynecol 2019;133:e320-56.

4 Thorne S, MacGregor A, Nelson-Piercy C. Risks of contraception and pregnancy in heart disease. Heart 2006;92:1520-5.

5 Burchill LJ, Lameijer H, Roos-Hesselink JW, et al. Pregnancy risks in women with pre-existing coronary artery disease, or following acute coronary syndrome. Heart 2015;101:525-9.

6 Elkayam U, Jalnapurkar S, Barakkat MN, et al. PregnancyAssociated acute myocardial infarction: a review of contemporary experience in 150 cases between 2006 and 2011. Circulation 2014;129:1695-702.

7 Blauwet LA, Delgado-Montero A, Ryo K, et al. Right ventricular function in peripartum cardiomyopathy at presentation is associated with subsequent left ventricular recovery and clinical outcomes. Circ Heart Fail 2016;9.

8 Chhabra N, Gupta A, Chibber R, et al. Outcomes and mortality in parturient and non-parturient patients with peripartum cardiomyopathy: a national readmission database study. Pregnancy Hypertens 2017;10:143-8.

9 Damp J, Givertz MM, Semigran M, et al. Relaxin-2 and soluble Flt1 levels in peripartum cardiomyopathy: results of the multicenter IpaC study. JACC Heart Fail 2016;4:380-8.

10 Duncker D, Haghikia A, König T, et al. Risk for ventricular fibrillation in peripartum cardiomyopathy with severely reduced left ventricular function-value of the wearable cardioverter/defibrillator. Eur $\mathrm{J}$ Heart Fail 2014;16:1331-6.

11 Ersbøll AS, Johansen M, Damm P, et al. Peripartum cardiomyopathy in Denmark: a retrospective, population-based study of incidence, management and outcome. Eur J Heart Fail 2017;19:1712-20.

12 Fett JD, Fristoe KL, Welsh SN. Risk of heart failure relapse in subsequent pregnancy among peripartum cardiomyopathy mothers. Int J Gynaecol Obstet 2010;109:34-6.

13 Gunderson EP, Croen LA, Chiang V. Epidemiology of peripartum cardiomyopathy: incidence, predictors, and outcomes. Obstet Gynecol 2011;118:583-91.

14 Haghikia A, Podewski E, Libhaber E, et al. Phenotyping and outcome on contemporary management in a German cohort of patients with peripartum cardiomyopathy. Basic Res Cardiol 2013;108:366. 
15 Haghikia A, Röntgen P, Vogel-Claussen J, et al. Prognostic implication of right ventricular involvement in peripartum cardiomyopathy: a cardiovascular magnetic resonance study. ESC Heart Fail 2015;2:139-49.

16 Haghikia A, Tongers J, Berliner D, et al. Early ivabradine treatment in patients with acute peripartum cardiomyopathy: subanalysis of the German PPCM registry. Int J Cardiol 2016;216:165-7.

17 Halkein J, Tabruyn SP, Ricke-Hoch M, et al. Microrna-146A is a therapeutic target and biomarker for peripartum cardiomyopathy. $J$ Clin Invest 2013;123:2143-54.

18 Hamdan R, Nassar P, Zein A, et al. Peripartum cardiomyopathy, place of drug therapy, assist devices, and outcome after left ventricular assistance. J Crit Care 2017;37:185-8.

19 Harper MA, Meyer RE, Berg CJ. Peripartum cardiomyopathy: population-based birth prevalence and 7-year mortality. Obstet Gynecol 2012;120:1013-9.

20 Hasan JA, Qureshi A, Ramejo BB, et al. Peripartum cardiomyopathy characteristics and outcome in a tertiary care hospital. J Pak Med Assoc 2010;60:377-80.

21 Hilfiker-Kleiner D, Haghikia A, Masuko D, et al. Outcome of subsequent pregnancies in patients with a history of peripartum cardiomyopathy. Eur J Heart Fail 2017;19:1723-8.

22 Kao DP, Hsich E, Lindenfeld J, Characteristics LJ. Characteristics, adverse events, and racial differences among delivering mothers with peripartum cardiomyopathy. JACC Heart Fail 2013;1:409-16.

23 Kezerle L, Sagy I, Shalev L, et al. A population-based study of peripartum cardiomyopathy in southern Israel: are Bedouin women a new high-risk group? Rambam Maimonides Med J 2018;9. doi:10.5041/RMMJ.10331. [Epub ahead of print: 1904 2018].

24 Kolte D, Khera S, Aronow WS, et al. Temporal trends in incidence and outcomes of peripartum cardiomyopathy in the United States: a nationwide Population-Based study. J Am Heart Assoc 2014;3:e001056.

25 Labbene I, Arrigo M, Tavares M, et al. Decongestive effects of levosimendan in cardiogenic shock induced by postpartum cardiomyopathy. Anaesth Crit Care Pain Med 2017;36:39-42.

26 Libhaber E, Sliwa K, Bachelier K, et al. Low systolic blood pressure and high resting heart rate as predictors of outcome in patients with peripartum cardiomyopathy. Int J Cardiol 2015;190:376-82.

27 Liu S, Zuberi SA, Malik AA, et al. Peripartum cardiomyopathy characteristics and outcomes in Canadian Aboriginal and nonAboriginal women. Can J Cardiol 2017;33:471-7.

28 McNamara DM, Elkayam U, Alharethi R. Clinical outcomes for peripartum cardiomyopathy in North America: results of the IpaC study (investigations of pregnancy-associated cardiomyopathy). $J$ Am Coll Cardiol 2015;66:905-14.

29 Modi KA, Illum S, Jariatul K, et al. Poor outcome of indigent patients with peripartum cardiomyopathy in the United States. Am J Obstet Gynecol 2009;201:171.e1-171.e5.

30 Mouquet F, Mostefa Kara M, Lamblin N, et al. Unexpected and rapid recovery of left ventricular function in patients with peripartum cardiomyopathy: impact of cardiac resynchronization therapy. Eur $J$ Heart Fail 2012;14:526-9.

31 AT N, Duan L, Win T. Maternal and fetal outcomes in pregnant women with heart failure. Heart 2018;104:1949-54.

32 Ntusi NBA, Badri M, Gumedze F, et al. Pregnancy-Associated heart failure: a comparison of clinical presentation and outcome between hypertensive heart failure of pregnancy and idiopathic peripartum cardiomyopathy. PLoS One 2015;10:e0133466.
33 Perveen S, Ainuddin J, Jabbar S. Peripartum cardiomyopathy: frequency and predictors and indicators of clinical outcome. J Pak Med Assoc 2016;66:1517-21.

34 Safirstein JG, Ro AS, Grandhi S, et al. Predictors of left ventricular recovery in a cohort of peripartum cardiomyopathy patients recruited via the Internet. Int J Cardiol 2012;154:27-31.

35 Saltzberg MT, Szymkiewicz S, Bianco NR. Characteristics and outcomes of Peripartum versus nonperipartum cardiomyopathy in women using a wearable cardiac defibrillator. J Card Fail 2012;18:21-7.

36 Sliwa K, Blauwet L, Tibazarwa K. Evaluation of bromocriptine in the treatment of acute severe peripartum cardiomyopathy: a proof-ofconcept pilot study. Circulation 2010;121:1465-73.

37 Sliwa K, Mebazaa A, Hilfiker-Kleiner D, et al. Clinical characteristics of patients from the worldwide registry on peripartum cardiomyopathy (PPCM): EURObservational research programme in conjunction with the heart failure association of the European Society of cardiology Study Group on PPCM. Eur $\checkmark$ Heart Fail 2017;19:1131-41.

38 Stapel B, Kohlhaas M, Ricke-Hoch M. Low STAT3 expression sensitizes to toxic effects of beta-adrenergic receptor stimulation in peripartum cardiomyopathy. Eur Heart J 2017;38:349-61.

39 van Spaendonck-Zwarts KY, Posafalvi A, van den Berg MP, et al. Titin gene mutations are common in families with both peripartum cardiomyopathy and dilated cardiomyopathy. Eur Heart $J$ 2014;35:2165-73.

40 Hilfiker-Kleiner D, Haghikia A, Berliner D, et al. Bromocriptine for the treatment of peripartum cardiomyopathy: a multicentre randomized study. Eur Heart J 2017;38:2671-9.

41 Ashikhmina E, Farber MK, Mizuguchi KA. Parturients with hypertrophic cardiomyopathy: case series and review of pregnancy outcomes and anesthetic management of labor and delivery. Int $J$ Obstet Anesth 2015;24:344-55.

42 Billebeau G, Etienne M, Cheikh-Khelifa R, et al. Pregnancy in women with a cardiomyopathy: outcomes and predictors from a retrospective cohort. Arch Cardiovasc Dis 2018;111:199-209.

43 Boyle S, Nicolae M, Kostner K, et al. Dilated cardiomyopathy in pregnancy: outcomes from an Australian tertiary centre for maternal medicine and review of the current literature. Heart Lung Circ 2019;28:591-7

44 Francia P, Adduci C, Musumeci B, et al. Autonomic cardiovascular control and cardiac arrhythmia in two pregnant women with hypertrophic cardiomyopathy: insights from ICD monitoring. Rev Port Cardiol 2018;37:351.e1-351.e4.

45 Gandjbakhch E, Varlet E, Duthoit G, et al. Pregnancy and newborn outcomes in arrhythmogenic right ventricular cardiomyopathy/ dysplasia. Int J Cardiol 2018;258:172-8.

46 Goland S, van Hagen IM, Elbaz-Greener G, et al. Pregnancy in women with hypertrophic cardiomyopathy: data from the European Society of cardiology initiated registry of pregnancy and cardiac disease (ROPAC). Eur Heart J 2017;38:2683-90.

47 Grewal J, Siu SC, Ross HJ, et al. Pregnancy outcomes in women with dilated cardiomyopathy. J Am Coll Cardiol 2009;55:45-52.

48 Hodes AR, Tichnell C, Te Riele ASJM, et al. Pregnancy course and outcomes in women with arrhythmogenic right ventricula cardiomyopathy. Heart 2016;102:303-12.

49 Joseph AC, Prapa M, Pellicori P, et al. Tachycardia-induced cardiomyopathy in pregnancy. J Cardiovasc Med 2016;17:762-6.

50 Katsuragi S, Omoto A, Kamiya C, et al. Risk factors for maternal outcome in pregnancy complicated with dilated cardiomyopathy. $J$ Perinatol 2012;32:170-5. 